\title{
A COMPARATIVE STUDY OF ANALGESIA IN PERIBULBAR AND SUB-TENON'S ANAESTHESIA IN MANUAL SMALL INCISION CATARACT SURGERY
}

\author{
M. R. Pujari ${ }^{1}$, Santosh V. Patil2, Kavita M. Salgar ${ }^{3}$, S. Pallavi Reddy 4 \\ 1 Professor, Department of Ophthalmology, M. R. Medical College, Gulbarga, Karnataka, India. \\ ${ }^{2}$ Associate Professor, Department of Ophthalmology, M. R. Medical College, Gulbarga, Karnataka, India. \\ ${ }^{3}$ Assistant Professor, Department of Ophthalmology, M. R. Medical College, Gulbarga, Karnataka, India. \\ ${ }^{4}$ Post Graduate Student, Departmem of Ophthalmology, M. R. Medical College, Gulbarga, Karnataka, India.
}

\section{ABSTRACT}

\section{BACKGROUND}

Blindness due to cataract presents an enormous problem in India, not just in terms of human morbidity but also in terms of economic loss and social burden. Cataract surgery constitutes by far the most common surgical procedure performed under local anaesthesia. Therefore, it is the need of the hour to make the anaesthetic technique painless and effective.

\section{OBJECTIVES}

To compare sub-tenon's anaesthesia and peribulbar anaesthesia with respect to pain/analgesia.

\section{METHODS}

This hospital based prospective study was conducted between December 2012 and May 2014 at Basaveshwar Teaching and General Hospital affiliated to M. R. Medical College, Gulbarga, Karnataka. During the above mentioned period, 200 randomly selected patients fulfilling the criteria framed were included for the study. They were randomly divided into group $P(n=100)$, who underwent manual small incision cataract surgery under peribulbar anaesthesia and group $S(n=100)$ patients underwent manual small incision cataract surgery by sub-tenon's anaesthesia. After the procedure the efficacy and safety of the two methods of anaesthesia in SICS with respect to intraoperative pain, akinesia, lid movements, rise in IOP and complications were compared.

\section{RESULTS}

Perioperative pain was dramatically lower in the sub-tenon's group of patients with significantly fewer patients experiencing unacceptable levels of pain.

\section{CONCLUSION}

Sub-tenon's anesthesia is recommended as a safe and effective alternative to peribulbar anaesthesia for small incision cataract surgery as it provides better analgesia.

\section{KEYWORDS}

Peribulbar Anaesthesia, Sub-tenon's Anaesthesia, Manual SICS.

HOW TO CITE THIS ARTICLE: M. R. Pujari, Santosh V. Patil, Kavita M. Salgar, S. Pallavi Reddy. "A Comparative Study of Analgesia in Peribulbar and Sub-tenon's Anaesthesia in Manual Small Incision Cataract Surgery." Journal of Evolution of Medical and Dental Sciences 2015; Vol. 4, Issue 100, December 14; Page: 16525-16528, DOI: 10.14260/jemds/2015/2459

\section{INTRODUCTION}

Blindness due to cataract presents an enormous problem in India, not just in terms of human morbidity but also in terms of economic loss and social burden. Cataract surgery constitutes by far the most common surgical procedure performed under local anaesthesia. Therefore, it is the need of the hour to make the anaesthetic technique painless and effective.

\section{Clinical Materials}

A prospective study was conducted in 200 patients having senile cataract who underwent cataract extraction by manual Small Incision Cataract Surgery (SICS) in Basaveshwar Teaching and General Hospital, Gulbarga, Karnataka, India with PCIOL implantation.

Financial or Other, Competing Interest: None.

Submission 04-11-2015, Peer Review 05-11-2015,

Acceptance 08-12-2015, Published 12-12-2015.

Corresponding Author:

Dr. S. Pallavi Reddy,

Post Graduate Student,

Department of Ophthalmology,

M. R. Medical College, Gulbarga, Karnataka, India

E-mail: pallavi_sanamreddy@hotmail.com

DOI:10.14260/jemds/2015/2459

\section{Inclusion Criteria}

1. Inpatients.

2. Senile cataract with $\mathrm{Dv}<6 / 36$.

3. Undergoing SICS with PCIOL implantation.

\author{
Exclusion Criteria \\ 1. Age $<30$ or $>90$. \\ 2. Glaucoma/LIG. \\ 3. Traumatic cataract. \\ 4. Complicated cataract. \\ 5. Subluxated/Dislocated lens. \\ 6. Previous intraocular injury/inflammation or surgery. \\ 7. Sensitivity to xylocaine. \\ 8. History of convulsions/epilepsy. \\ 9. Inability to give informed consent.
}

The patients were randomly divided into 2 groupsgroup $\mathrm{P}$ for those to be operated under peribulbar block and group $S$ for those to be operated under sub-tenon's block. Grading of pain was done during the administration of anaesthesia, intraoperatively and postop (4 hours after surgery). 


\begin{tabular}{|c|c|}
\hline Grade 0 & No pain. \\
\hline Grade 1 & Slight sensation \\
\hline Grade 2 & Slight pain \\
\hline Grade 3 & Moderate pain \\
\hline Grade 4 & Intense pain \\
\hline
\end{tabular}

\section{TECHNIQUE OF PERIBULBAR ANESTHESIA}

\section{Preparation of Anesthetic Solution:}

Lignocaine $2 \%$ with adrenaline $1: 200000$ is used. Hyaluronidase $1500 \mathrm{IU}$ is dissolved in $30 \mathrm{ml}$ of $2 \%$ lignocaine with adrenaline (1:200000) resulting in $50 \mathrm{IU} / \mathrm{ml}$ of anesthetic mixture.

\section{Patient Position: Supine.}

Skin Preparation: 5\% betadine solution is to be painted on skin around eye.

Technique: Patient is asked to look in primary gaze. A $5 \mathrm{ml}$ syringe with 24 gauge $2.5 \mathrm{~cm}$ needle is taken. The initial injection is injected inferior-temporally at the lower orbital margin midway between lateral canthus and lateral limbus. The needle is advanced parallel to the plane of the orbital floor till $2.5 \mathrm{~cm}$ and $3 \mathrm{ml}$ of anesthetic solution injected after careful aspiration to rule out intra-vascular placements. At supero-nasal margin of orbit a second injection is given; the needle advanced to about $2.5 \mathrm{~cm}$ along the roof and $2 \mathrm{ml}$ of anesthetic solution injected. Repeat injection of $2-3 \mathrm{ml}$ will be given at inferotemporal margin for patients who do not develop adequate akinesia and analgesia.

\section{TECHNIQUE OF SUB-TENON'S ANESTHESIA}

\section{Preparation of Anesthetic Solution}

Lignocaine $2 \%$ with adrenaline 1:200000 will be used. Hyaluronidase 1500 IU will be dissolved in $30 \mathrm{ml}$ of $2 \%$ lignocaine with adrenaline (1:200000) resulting in $50 \mathrm{IU} / \mathrm{ml}$ of anesthetic mixture.

\section{Patient Position}

Supine.

\section{Skin Preparation}

$5 \%$ betadine solution will be painted on skin around eye.

\section{Technique:}

It is to be performed in the operation theatre under aseptic conditions. Conjunctiva is anesthetized by instilling $4 \%$ lignocaine eye drops 2-4 times. After anesthetizing conjunctiva, suitable wire speculum is inserted, a button hole is made in conjunctiva along the tenon's capsule $3 \mathrm{~mm}$ from the limbus in the infero-nasal quadrant. The infero-nasal quadrant is accessed by asking the patient to look upwards and outwards.

Then by holding conjunctiva along with tenon's capsule the capsule is dissected $2-3 \mathrm{~mm}$ along the sclera. A $2 \mathrm{~mm}$ wide $2.2 \mathrm{~cm}$ 24-gauge curved blunt cannula is inserted into sub-tenon's space and passed posteriorly on the sclera until its tip lays behind the equator of globe where $3 \mathrm{ml}$ of anesthetic solution is delivered into sub-tenon's space.

\section{SURGERY}

All patients will undergo manual small incision cataract surgery after administration of the anesthesia.
RESULTS

\begin{tabular}{|c|c|c|c|c|}
\hline \multirow{2}{*}{$\begin{array}{c}\text { Grading of } \\
\text { Pain }\end{array}$} & \multicolumn{2}{|c|}{ Peribulbar (P) } & \multicolumn{2}{c|}{ Sub-Tenon's (S) } \\
\cline { 2 - 5 } & No. & $\mathbf{\%}$ & No. & \% \\
\hline 1 & 0 & 0.0 & 30 & 30.0 \\
\hline 2 & 44 & 44.0 & 62 & 62.0 \\
\hline 3 & 56 & 56.0 & 8 & 8.0 \\
\hline Total & $\mathbf{1 0 0}$ & $\mathbf{1 0 0 . 0}$ & $\mathbf{1 0 0}$ & $\mathbf{1 0 0 . 0}$ \\
\hline Comparison of Pain during Administration of Block \\
\hline
\end{tabular}

$\chi^{2}=48.07, \mathrm{p}<0.001$ very highly significant

BAR GRAPH SHOWING COMPARISON OF PAIN DURING ADMINISTRATION

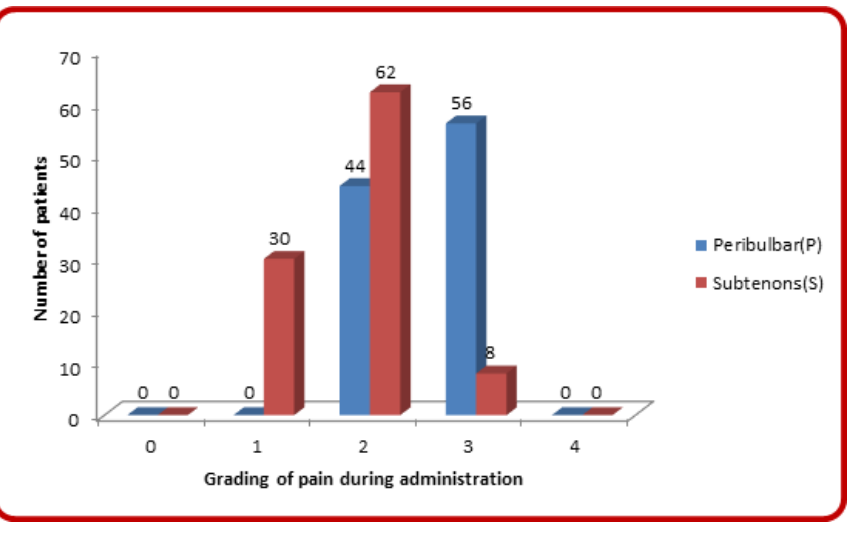

\begin{tabular}{|c|c|c|c|c|}
\hline \multirow{2}{*}{$\begin{array}{c}\text { Grading of } \\
\text { Pain }\end{array}$} & \multicolumn{2}{|c|}{ Peribulbar (P) } & \multicolumn{2}{c|}{ Sub-Tenon's (S) } \\
\cline { 2 - 5 } & No. & $\mathbf{\%}$ & No. & \% \\
\hline 0 & 32 & 32.0 & 72 & 72.0 \\
\hline 1 & 49 & 49.0 & 21 & 21.0 \\
\hline 2 & 16 & 16.0 & 5 & 5.0 \\
\hline 3 & 3 & 3.0 & 2 & 2.0 \\
\hline Total & 100 & 100.0 & 100 & 100.0 \\
\hline \multicolumn{3}{|c|}{ Intraoperative Comparison of Pain } \\
\hline
\end{tabular}

$\chi^{2}=31.8, \mathrm{p}<0.001$ very highly significant

BAR GRAPH SHOWING INTRAOPERATIVE COMPARISON OF PAIN

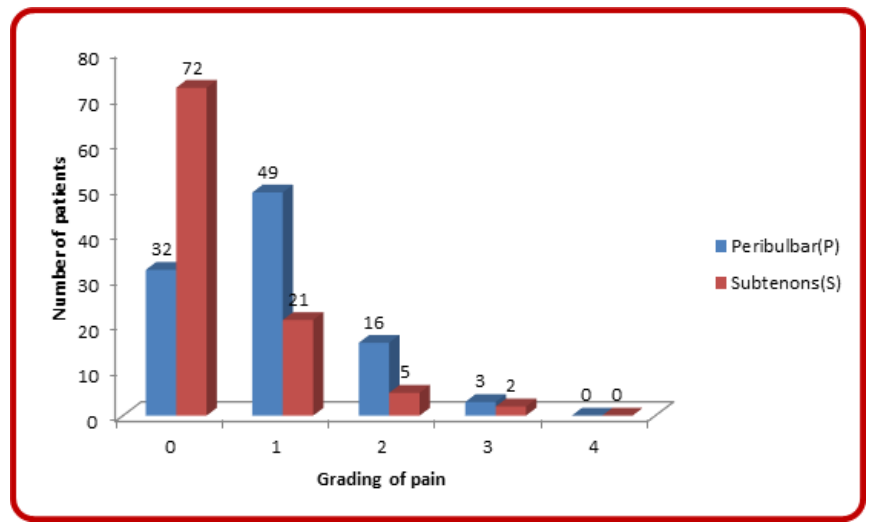

\begin{tabular}{|c|c|c|c|c|}
\hline $\begin{array}{c}\text { Grading of } \\
\text { Pain }\end{array}$ & Peribulbar (P) & \multicolumn{2}{c|}{ Sub-Tenon's (S) } \\
\cline { 2 - 5 } & No. & $\mathbf{\%}$ & No. & \% \\
\hline 0 & 3 & 3.0 & 19 & 19.0 \\
\hline 1 & 43 & 43.0 & 54 & 54.0 \\
\hline 2 & 47 & 47.0 & 27 & 27.0 \\
\hline 3 & 7 & 7.0 & 0 & 0.0 \\
\hline Total & 100 & 100.0 & 100 & 100.0 \\
\hline \multicolumn{4}{|c|}{ Post-operative Comparison of Pain } \\
\hline
\end{tabular}

$\chi^{2}=41.62, \mathrm{p}<0.001$ very highly significant 
Bar Graph showing Post-operative Comparison of Pain

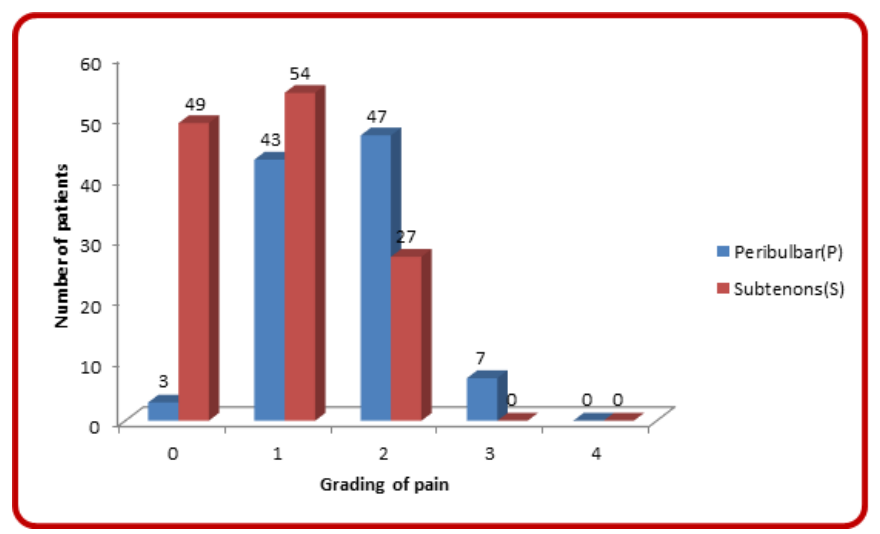

The peribulbar group P experienced a significantly higher levels of pain when compared to the sub-tenon's group $S$ with $72 \%$ of the $S$ group having experienced 0 grade of pain when compared to $32 \%$ of the P group intraoperatively. A $3 \%$ of the $\mathrm{P}$ group experienced grade 3 pain as compared to $2 \%$ of the $\mathrm{S}$ group during the surgery. During the administration of anaesthesia $56 \%$ of the $\mathrm{P}$ group had grade 3 pain, whereas $62 \%$ of the $S$ group had grade 2 pain. Four hours postoperatively, $19 \%$ of the $S$ group was pain free compared to only $3 \%$ of the P group.

\section{COMPARISON WITH OTHER STUDIES}

\begin{tabular}{|c|c|c|c|c|c|c|}
\hline \multirow{2}{*}{$\begin{array}{c}\text { Intra } \\
\text { operative } \\
\text { pain }\end{array}$} & \multicolumn{2}{|c|}{ OUR STUDY } & \multicolumn{2}{c|}{ PARKAR TASNEEM, et al. } & \multicolumn{2}{c|}{ ABHIJIT DATTA, et al. } \\
\cline { 2 - 7 } & SUB-TENON & PERIBULBAR & SUB-TENON & PERIBULBAR & SUB-TENON & PERIBULBAR \\
\hline $\begin{array}{c}\text { Total no. of } \\
\text { Patients }\end{array}$ & 100 & 100 & 80 & 88 & 40 & 40 \\
\hline GRADE 0 & $32(32 \%)$ & $72(72 \%)$ & $62(77.4 \%)$ & $31(35.2 \%)$ & $18(44 \%)$ & $17(42.5 \%)$ \\
\hline GRADE 1 & $49(49 \%)$ & $21(21 \%)$ & $16(20 \%)$ & $47(53.4 \%)$ & $15(39 \%)$ & $17(42.5 \%)$ \\
\hline GRADE 2 & $16(16 \%)$ & $5(5 \%)$ & $1(1.3 \%)$ & $7(7.1 \%)$ & $3(7.5 \%)$ & $2(5 \%)$ \\
\hline GRADE 3 & $3(3 \%)$ & $2(2 \%)$ & $1(1.3 \%)$ & $2(2.3 \%)$ & $3(7.5 \%)$ & $2(5 \%)$ \\
\hline GRADE 4 & $0(0 \%)$ & $0(0 \%)$ & $0(0 \%)$ & $1(1.0 \%)$ & $1(2 \%)$ & $2(5 \%)$ \\
\hline
\end{tabular}

\section{DISCUSSION}

In 1985, Davis and Mandel. ${ }^{1}$ reported the use of peribulbar anesthesia. But Kelman was known to have first performed this technique (Unpublished) in 1970. Peribulbar technique was rapidly accepted as it was effective and relatively safe when compared to retrobulbar anaesthesia.

Sub-Tenon's Block (STB) was first described by Turnbull. ${ }^{2}$ in 1884 and later by Swan. ${ }^{3}$ in 1956. It was revisited in the 1990 s by several workers, first of whom was Hansen. ${ }^{4}$ et al. in the USA.

A study by Roman SJ. ${ }^{5}$ et al. in Paris, France, found that there were no anaesthesia related complications associated with this technique. The administration of the block was painless for $99.1 \%$ of the patients. In all, $97.3 \%$ reported no pain during surgery.

Briggs MC. ${ }^{6}$ et al. in UK found that the pain scores for administration of anaesthetic were significantly lower for subTenon's anaesthesia (Mean 1.4) compared with the peribulbar technique (Mean 2.4). Also per-operative pain scores for subTenon's anaesthesia (mean 0.5) were lower than those for peribulbar anaesthesia (Mean 1.2), but not significantly so.

An Indian study by Tasneem Parkar, et al. ${ }^{7}$ randomised 168 patients to sub-tenon and peribulbar groups. Pain during administration of anaesthesia during surgery and $4 \mathrm{~h}$ after surgery was graded on a visual analogue pain scale and compared for both the techniques. Thirty-one out of 88 $(35.2 \%)$ patients of peribulbar group and 62/80(77.5\%) of sub-tenon group experienced no pain during administration of anaesthesia. There was no significant difference in pain during and $4 \mathrm{~h}$ after surgery. The study concluded that sub-tenon's anaesthesia is safe and as effective as peribulbar anaesthesia and is more comfortable to the patient at the time of administration.

These findings were consistent with those of Datta. ${ }^{8}$ et al. Inadequately controlled pain has undesirable physiologic and psychologic consequences such as increased postoperative morbidity, delayed recovery, a delayed return to normal daily living and reduced patient satisfaction. ${ }^{9}$
Consequences of acute pain.9,10

\begin{tabular}{|l|l|}
\hline Cardiovascular & $\begin{array}{l}\text { Tachycardia, hypertension, increase } \\
\text { in cardiac workload }\end{array}$ \\
\hline Pulmonary & $\begin{array}{l}\text { Respiratory muscle spasm, } \\
\text { decreased vital capacity, hypoxia, } \\
\text { increase in risk of respiratory } \\
\text { infection }\end{array}$ \\
\hline Immunologic & Impaired immune function \\
\hline Psychological & $\begin{array}{l}\text { Anxiety, fear and frustration results } \\
\text { in poor patient satisfaction }\end{array}$ \\
\hline
\end{tabular}

Also, the lack of adequate postoperative pain treatment may lead to persistent pain after surgery, which is often overlooked. ${ }^{9}$

\section{CONCLUSION}

Pain was dramatically lower in sub-tenon group of patients with significantly fewer patients experiencing unacceptable levels of pain during the administration of block, intraoperatively and postoperatively ( 4 hours). It can be concluded that sub-tenon's anaesthesia provides a better alternate to the time tested peribulbar anaesthesia.

\section{REFERENCES}

1. Davis DB II, Mandel MR: Posterior peribulbar anesthesia: An alternative to retrobulbar anesthesia. J Cat Refract Surg 12:182, 1986.

2. Turnbull CS: Editorial. Med Surg Rep 29:628, 1884.

3. Swan KC. New drugs and techniques for ocular anaesthesia. Trans Am Acad Ophthalmol Otolaryngol. 1956;60(3):368-375.

4. Hansen EA, Mein CE, Mazzoli R: Ocular anesthesia for cataract surgery: A direct sub-Tenon's approach. Ophthalmic Surg 21:696, 1990. 
5. Roman SJ, Chong Sit DA, Boureau CM, et al. Sub-tenon's anaesthesia: an efficient and safe technique. $\mathrm{Br} \mathrm{J}$ Ophthalmol 1997;81(8):673-676.

6. Briggs MC, Beck SA, Esakowitz L. Sub-Tenon's versus peribulbar anaesthesia for cataract surgery Eye (Lond). 1997;11(Pt 5):639-43.

7. Parkar T, Gogate P, Deshpande M, et al. Comparison of sub-tenon anaesthesia with peribulbar anaesthesia for manual small incision cataract surgery. Indian J Ophthalmol 2005;53:255-9.
8. Datta A, Ghosh KA, Basu S, et al. Exploring the anaesthetic options for Manual Small Incision Cataract Surgery (MSICS): A Comparative evaluation of peribulbar, subtenon's and topical anaesthesia. AIOC 2008 proceedings; 82.

9. Joshi GP, Ogunnaike BO. Consequences of inadequate postoperative pain relief and chronic persistent postoperative pain. Anesthesiol Clin North America. 2005 Mar;23(1):21-36.

10. Rowlingson JC. Update on acute pain management. International Anaesthesia Research Society Review Course Lectures 2006:95. 